\title{
Bladder Sparing Approaches for Muscle-Invasive Bladder Cancers
}

\author{
Omar M. S. El-Taji, MBChB, MRes ${ }^{1}$ \\ Sameer Alam, $B S C^{2}$ \\ Syed A. Hussain, MBBS, MSC, MD, FRCP ${ }^{2, *}$
}

\author{
Address \\ ${ }^{1}$ Department of Surgery, St. Helen's and Knowsley NHS Teaching Hospitals, \\ University of Liverpool, Prescot, L35 5DR, UK \\ *,2Department of Molecular and Clinical Cancer Medicine, University of Liverpool, \\ Liverpool, L69 3GA, UK \\ Email: syed.hussain@liverpool.ac.uk
}

Published online: 4 March 2016

(c) The Author(s) 2016. This article is published with open access at Springerlink.com

This article is part of the Topical Collection on Genitourinary Cancers

Keywords Bladder cancer $\cdot$ Muscle-invasive $\cdot$ Bladder sparing $\cdot$ Organ preservation $\cdot$ Bladder preservation $\cdot$ Chemoradiation

\section{Opinion statement}

Organ preservation has been increasingly utilised in the management of muscle-invasive bladder cancer. Multiple bladder preservation options exist, although the approach of maximal TURBT performed along with chemoradiation is the most favoured. Phase III trials have shown superiority of chemoradiotherapy compared to radiotherapy alone. Concurrent chemoradiotherapy gives local control outcomes comparable to those of radical surgery, but seemingly more superior when considering quality of life. Bladder-preserving techniques represent an alternative for patients who are unfit for cystectomy or decline major surgical intervention; however, these patients will need lifelong rigorous surveillance. It is important to emphasise to the patients opting for organ preservation the need for lifelong bladder surveillance as risk of recurrence remains even years after radical chemoradiotherapy treatment. No randomised control trials have yet directly compared radical cystectomy with bladder-preserving chemoradiation, leaving the age-old question of superiority of one modality over another unanswered. Radical cystectomy and chemoradiation, however, must be seen as complimentary treatments rather than competing treatments. Meticulous patient selection is vital in treatment modality selection with the success of recent trials within the field of bladder preservation only being possible through this application of meticulous selection criteria compared to previous decades. A multidisciplinary approach with radiation oncologists, medical oncologists, and urologists is needed to closely monitor patients who undergo bladder preservation in order to optimise outcomes. 


\section{Introduction}

Bladder tumours are the 2nd most common genitourinary tumours and the 9th most common cause of cancer-associated morbidity worldwide [1]. In the USA for 2015, it is estimated that 74,000 new cases of bladder cancer (BC) will be diagnosed, and there will be an estimated 16,000 cases of BC-associated mortality [2]. It signifies the most common urinary tract malignancy, with a metastatic bladder cancer median survival rate that seldom exceeds 15 months. A changing age distribution of western societies and a progressing bequest of cigarette smoking have meant that bladder-related cancers have accelerated, becoming a significant cause of death [3].

When comparing the 5-year relative survival rates of the most common UK malignancies from 1970 to 2009, all malignancies show a rise in relative survival across the years, apart from $\mathrm{BC}$ which shows a $12.5 \%$ reduction in relative survival from 1991 to 2009 (Fig. 1) [4]. The management of muscle-invasive bladder cancer (MIBC) remains a multifactorial challenge as well as the eradication of local disease, the eradication of micrometastasis, and finally the maintenance of an optimal quality of life.

Considering that the mean age at diagnosis is 70 , and the single most significant risk factor is smoking, many patients present with existing co-morbidities, rendering certain interventions highly risky and therefore presenting limited options for treatment. At initial presentation, $30 \%$ of patients are diagnosed with a muscle-invasive tumour. From the remainder of patients that had been diagnosed with a non-muscle invasive tumour at presentation, $30 \%$ go on to develop muscle-invasive disease during follow-up [5]. With the highest predisposition to relapse of any malignancy, patients with $\mathrm{BC}$ require regular surveillance and close followup during and, more significantly, in succeeding therapy [6]. The management of bladder tumours has remained largely unchanged over the last few decades. The assumed gold standard treatment for organ-confined MIBC is radical cystectomy (RC), with bilateral dissection of pelvic lymph nodes (PLND). Although RC aims to be curative, at least half of patients with muscleinvasive disease develop metastasis within a 2-year period and subsequently die [7]. Furthermore, patients undergoing RC will often be left with a replacement voiding system which uses autologous segments of gastrointestinal tissue [8]. This is often achieved through ileal conduit urinary diversion, orthotopic bladder substitution or continent cutaneous diversion [9, 10]. Whilst radical extirpation of the bladder can be successful, from an oncological perspective, substantial morbidity is associated with enteric interposition of gastrointestinal tissue within the urinary tract $[11,12]$. Surgical intervention itself requires procedures on the urinary and gastrointestinal tracts which are associated with complication rates of approximately $61 \%$ [13]. The average post-operative length of stay ranges from 7 to 14 days with a post-operative 90-day readmission rate of $32 \%$ as demonstrated by Aghazadeh et al. [14-16]. In a similar study, Goodney et al. reported a 30-day readmission rate of $21 \%$, the second highest rate of any surgical procedure, only surpassed by mitral valve replacement (22\%) [16].

Despite continent reconstruction of the urinary tract using cutaneous reservoirs or orthotopic diversions being a stepup from ileal conduit urinary diversion, a

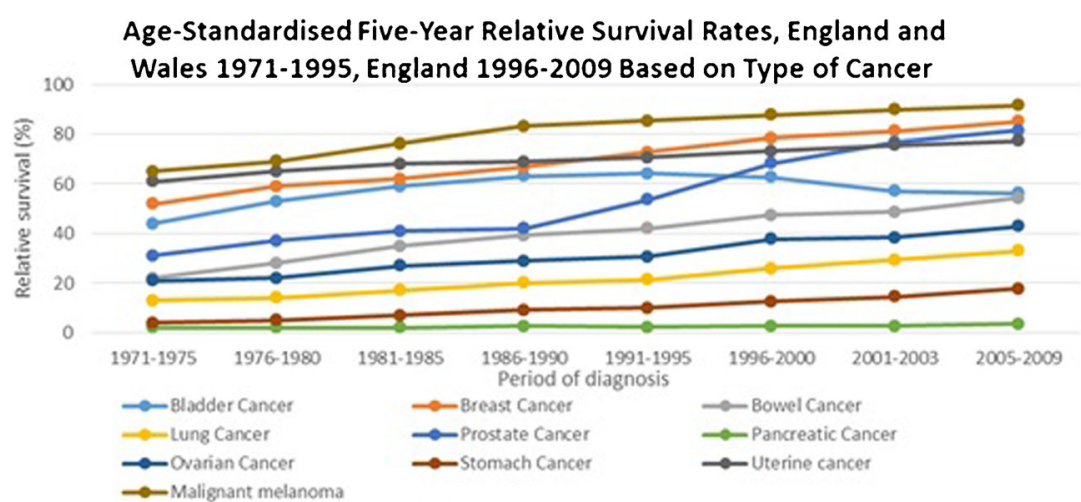

Fig. 1. Age-standardized 5-year relative survival rates, England and Wales 1971-1995, England 1996-2009 based on type of cancer 
limited number of patients in practice will have continent urinary reconstruction [17]. Moreover, whilst the use of tissue engineering in the field of bladder reconstruction post-cystectomy shows great potential, its clinical application in mainstream urological practice seems still quite a way off [18]. The use of bladder-sparing approaches with regards to MIBC has been extensively investigated over the past two decades. These approaches have been developed to address the needs of two main cohorts: patients with severe medical comorbidities for whom a radical surgery is too high risk and patients with limited disease who wish to avoid radical surgery.

The general consensus is that single-modality bladder-preserving approaches consisting of chemotherapy, radiotherapy or transurethral resection of bladder tumour (TURBT) are inferior and often yield inferior results for local tumour control and long-term survival in MIBC. Consequently, dual/trimodality regimens have been used to attempt to replicate the outcomes of $\mathrm{RC}$, whilst avoiding the morbidity and impact on quality of life associated with radical therapy. The trimodality approach involves an extensive TURBT, attempting to achieve complete resection. Complete resection may not always be possible, and incomplete resection is associated with a reduced disease-free survival [19]. Induction therapy then follows with surveillance cystoscopy and biopsy to assess clinical response. Complete responders will progress to chemoradiation whilst non-responders will undergo cystectomy.

Historically, bladder-sparing approaches were initially used in patients who were not candidates for surgery; however, despite this poorly selected population, the 5year local control rate for these patients was 20-40\% whilst overall survival (OS) was $50 \%$ [20-23]. These results were always seen to be inferior to surgery, and therefore their role in the immediate management of $\mathrm{BC}$ was rarely explored in a more selective cohort of patients.

Phase I and II trials in the 1980s showed that metastatic BCs are chemosensitive, fostering hope of cure. Various treatment algorithms have been proposed to aid in patient selection for bladder preservation and their risk stratification towards appropriate treatment options-no doubt the most vital factors in BC management [24]. Although accumulated data over the last 20 years has suggested that concomitant chemoradiation in MIBC gives equivalent results to those of RC, it has never been formally compared in a randomised control trial.
The difficulty in achieving both complete treatment response whilst ensuring bladder function remains acceptable and has driven urologists and oncologists to work together to develop multimodal approaches to MIBC. Here, we present a review of the current literature related to the bladder sparing approaches for MIBC.

\section{Radical TUR}

TUR involves the transmural resection of the bladder wall and resecting all visible tumours as far out as the perivesical connective tissue [25]. This extensive resection comes with significant risks including bladder perforation and increased risk of tumour dissemination through extravesical seeding [26].

Primarily, the rationale behind radical TUR as the only treatment is the discovery of pT0 at RC in those previously only treated with TUR before surgery. Studies have shown a $>10 \%$ incidence of pT0 at RC [27-30]. Furthermore, $42 \%$ of those with cT2a disease have been shown to have pT0 disease after visibly completing TUR [30]. Even those with pT0 are not all truly free of disease as recurrence-free survival (RFS) has been reported as 92 and $86 \%$ at 5 and 10 years, respectively [28].

The overall consensus amongst the majority of experts is that TUR alone is inadequate for a diagnosis of MIBC. The reasons behind this are extensive; however, one factor deemed significant is the high rate of upstaging at RC. Studies have demonstrated upstaging from cT2 to pT3 as high as $39.7 \%$ [31] with lymph node metastasis at the time of cystectomy at $23 \%$ as reported in several series $[28,31,32]$. Patient selection is therefore vital and is often used as a last resort for those unwilling or unfit to undergo more aggressive treatment. Although limited data exists for long-term outcomes of radical TUR, two prospective studies have been the basis of radical TUR monotherapy with distinctive results (Table 1).

It is vital to adopt appropriate and accurate patient selection when choosing candidates which may have successful outcomes from radical TUR as detailed in the above studies. Ideal candidates boasted no evidence of advanced clinical stage disease, tumours $<3 \mathrm{~cm}$, and negative bed biopsies at initial TUR or negative restaging TUR [33-35].

Surveillance and rigorous follow-up similar to that in the study by Solsona et al. may not be feasible. Monotherapy showed inadequacies in patients who developed disease reoccurrence, and, therefore, 


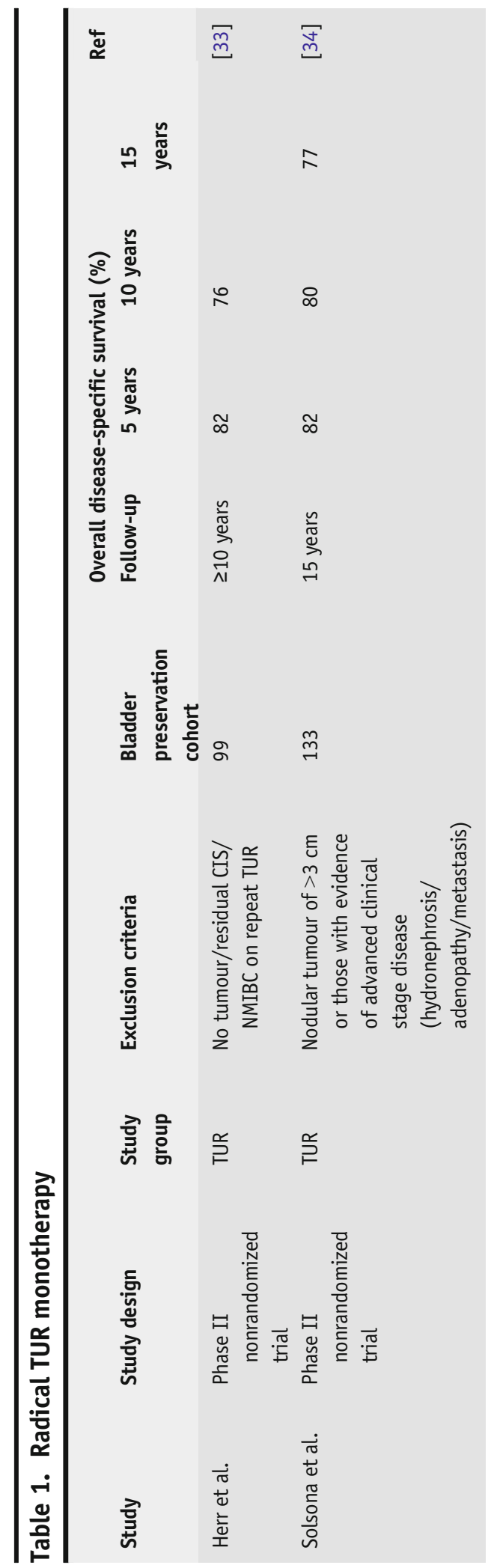


for these patients more aggressive treatment with multimodal approaches could be beneficial. These patients eventually required RC or further treatment for residual disease/local relapse [33, 34]. BCs are known to have the highest susceptibility of recurrence and progression of any malignancy. With such high odds of recurrence, $\mathrm{BC}$ has produced the most expensive management protocol of any malignancy, costing the National Health Service approximately $£ 55.39$ million in the UK per annum [6].

\section{Radiotherapy}

Conventionally, radiotherapy is administered externally in a typical dose schedule of $64 \mathrm{~Gy}$ in 32 fractions or hypofractionated schedules such as 55 Gy in 20 fractions, both shown to be equally as effective in the long

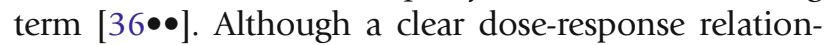
ship has not been identified, studies including a multivariant analysis have shown poorer outcomes when using doses less than 57.5 Gy $[37,38]$. It is important, however, to appreciate that increasing dosages of radiotherapy is closely linked with toxicity, but the majority of modern regimens are tolerated well and long-term bladder function is seldom effected [39]. Despite its merits, however, its use has declined markedly since the 1980s and radiotherapy alone is now used only in circumstances where other treatment modalities have failed, or in advanced disease. It is important to note that radiotherapy is seldom used alone and that the majority of patients have often already undergone prior TUR.

Although surgery is considered the standard of care in the majority of patients, considerable interest in bladder preservation has led to radiotherapy re-emerging as an effective alternative, particularly in patients who are not fit for radical surgery. Due to the cohorts that are treated with radiotherapy, it is often difficult to compare outcomes of radiotherapy with surgery. Patients undergoing radical radiotherapy in comparison with surgical candidates often have multiple co-morbidities with worse prognostic factors and poorer performance statuses $[40,41]$. It is for these reasons that studies have reported relatively high rates of incomplete response and local recurrences that reach up to $50 \%$ [42].

Studies have demonstrated outcomes that remain inferior to multimodal treatment modalities, with a 5year overall survival (OS) of 26-50\% and local control rates of approximately $50 \%$ [22, 43-49].

Pollack et al. assessed response to radiotherapy in different tumour stages and reported a 5-year OS for T2 to be $40-59 \%$ and $0-50 \%$ for T3 [45]. In a similar study, Pollack et al. reported local long-term control rates after radiotherapy alone in T3b at $27 \%$ [20]. Factors that have been found to be statistically significant in prognosticating local failure are tumour multiplicity, ureteric obstruction and higher T stage [22].

Shipley et al. evaluated data from 55 patients treated with radiotherapy alone in order to identify factors associated with tumour radio responsiveness. Sixty-seven percent of patients presented with $\mathrm{T} 2$ or $\mathrm{T} 3$ tumours with the remainder of patients having T4 tumours. OS after 5 years was $28 \%$; however, when comparing patients who possessed T2/3 with those having T4 disease, survival after 5 years was 45 and $9 \%$, respectively. The T2/3 group demonstrated that the most vital prognostic factor was histological finding of tumour on papillary surface, in the absence of urethral obstruction, and in less advanced clinical stages, factors that were similarly found by Pollack et al. [19, 45].

It is important to mention, however, that both population-based studies and large surgical and radiotherapy-based series have shown similar longterm survival rates and no survival difference linked to mode of treatment $[28,48,50]$. Additionally, the vast majority of these large-scale surgical series have population medians which are well below the disease population, signifying its lack of application in patients with invasive bladder disease [28]. In a large populationbased series, Munro et al. investigated the outcomes of 458 patients with MIBC undergoing RC versus radiotherapy. OS was similar in the two groups, $22 \%$ for those undergoing radiotherapy, and $24 \%$ in the group undergoing RC [51].

Although chemoradiotherapy has much better outcomes as a treatment option in comparison with radiotherapy alone, a small proportion of patients will not be candidates for dual therapy and radiotherapy alone may be the only treatment option available. A highly conclusive study by James et al. demonstrated that chemoradiotherapy significantly improved loco-regional control of BC with no significant increase in adverse events compared with radiotherapy alone. They also provided evidence, which would suggest that RT alone does have at least some curative potential. Loco-regional DFS at 2 and 5 years was 54 and $35 \%$, respectively [36••].

\section{Chemotherapy}

Chemotherapy has been used for decades in the management of MIBC as neoadjuvant or adjuvant adjuncts to primary $\mathrm{RC}$ or as an organ preservation treatment. This has shown to reduce the risk of micrometastasis, 
improving survival $[52,53]$. A recent international multicentre-randomised phase III trial investigated the use of neoadjuvant cisplatin, methotrexate and vinblastine (CMV) chemotherapy in patients with MIBC treated by cystectomy and/or radiotherapy [54]. This trial demonstrated long-term statistically significant reduction in risk of death and a $6 \%$ increase in a 10-year survival after CMV therapy, compared with radiotherapy or RC alone. The addition of paclitaxel to GC demonstrated superiority through a higher response rate as well as survival benefit which did not reach statistical significance [55]. Chemotherapy alone does not play any role in the management of MIBC.

\section{Synchronous Chemoradiation}

The first bladder preservation studies were conducted in the early 1980s and were found to demonstrate encouraging results [47, 48, 56-59]. Rationale that supports the addition of chemotherapy to radiotherapy is based on four main principals. Firstly, the evidence of micrometastasis exists concurrently with invasive BC. In a study of 367 individuals at autopsy, $68 \%$ demonstrated distant metastasis, with frequency of metastasis increasing with tumour stage as one would expect (pT2 $36 \%$, pT3a $45 \%$, pT3b $69 \%$ and pT4 $79 \%$ ) [60].This is supported by the high probability of consequent distant metastasis post-cystectomy or radiotherapy alone by approximately $50 \%$ after 2 years [28]. This suggests that combination therapy would reduce the likelihood of distant metastasis by tackling micrometastatic disease. Secondly, the use of radiotherapy on its own can cause the development of vascular sclerosis after a period of months, thus increasing the likelihood of chemotherapeutic failure [61]. Thirdly, the prime time to tackle potential micrometastatic cells is prior to the development of gross metastatic disease. Finally are the radiosensitising properties of certain chemotherapeutic agents, e.g., gemcitabine, mitomycin $\mathrm{C}$ and 5fluorouracil [62].

Although a variety of phase I and II trials have demonstrated on the whole good tolerability and feasibility when assessing chemoradiation, data is still lacking with very few trials that compare synchronous chemoradiation with radiation alone [42, 48, 63-74]. In fact, the only randomised trial of this approach before BC2001

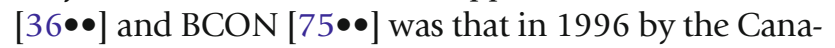
dian Cancer Society Research Institute [57]. This study randomised 99 patients to receive radiotherapy of $40 \mathrm{~Gy}$ in 20 fractions alone or radiotherapy with the same schedule combined with cisplatinum $100 \mathrm{mg} / \mathrm{m}^{2}$ twice weekly for 3 weeks, followed by elective cystectomy or further radiotherapy. Those who had received combined therapy had a significantly lower rate of loco-regional recurrence compared to those receiving radiotherapy alone ( 40 vs $59 \% p=0.026$ ). Statistically, no significant results were obtained for bladder preservation (70\% vs $36 \% p=0.14$ ) and OS (47\% vs $33 \% p=0.34)$. Although this is a small study with limited power, the promising results justified further investigation.

Many studies have evaluated the efficacy of synchronous chemoradiation compared to radiotherapy alone in tumours arising from primary sites other than the bladder [76-78]. These studies suggested a substantial advantage in local control and reduction in odds of death with combined therapy. One such study is the UKCCCR, which compared radiotherapy with synchronous chemotherapy in anal cancer [78]. Here, patients were randomised to receive radiotherapy alone or radiotherapy with 5-fluorouracil (5FU) by continuous infusion during the first and last weeks of radiotherapy in addition to mitomycin $\mathrm{C}$ on day 1 of the first fraction of radiotherapy. The significance of this study in the management of $\mathrm{BC}$ came about because of the significant prevalence of renal impairment amongst the vast majority of BC patients. Cisplatin itself requires an adequate GFR ( $>60 \mathrm{~mL} / \mathrm{min}$ ) for it to be safely delivered and to justify its side effect profile [79]. When comparing the dosing regimen from the Canadian study to our institution, the vast majority of patients would be deemed unfit to receive cisplatin at those doses. Our previous work has demonstrated in a phase I trial that radiotherapy and concurrent chemotherapy with mitomycin $\mathrm{C}$ and 5FU are feasible with acceptable toxicity in patients with poor prognosis [73]. Hussain et al. then subsequently conducted a phase II trial investigating synchronous chemoradiotherapy with mitomycin $\mathrm{C}$ and infusional 5FU in MIBC. We reported the long-term toxicity and efficacy results with the optimised regimen. Patients were administered mitomycin and 5FU for 5 days during weeks 1 and 4 of radiotherapy (55 Gy in 20 fractions). OS was $68 \%$ (12 months), $49 \%$ (36 months) and $36 \%$ (60 months). It is worth noting that many patients entering our phase I/II study were deemed unfit for radical cystectomy. Local and distant progression free rates were 82 and $86 \%$ at 12 and 24 months, respectively, and 79 and $75 \%$ at 24 months. We concluded that using multimodality therapy is feasible and safe in patients with poor renal function [80]. Choudhury et al. demonstrated in a phase II trial a high response rate, durable local control, and acceptable 
toxicity in patients treated with concurrent chemoradiotherapy using gemcitabine [74].

James et al., following on from the phase I/II study, demonstrated in a phase III randomised control trial comparing TURBT with either synchronous chemoradiation (mitomycin $\mathrm{C}$ and 5FU) or with radiotherapy alone (either 55 Gy in 20 fractions over 4 weeks or 64 Gy in 32 fractions over 6.5 weeks) that chemoradiation significantly improved loco-regional control of BC with no significant increase in adverse events compared

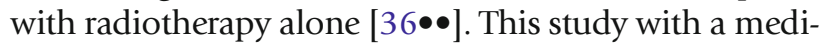
an follow-up of 69.9 months demonstrated a relative reduction in loco-regional recurrence of $35 \%$ and almost halving of invasive recurrence. At 2 years, locoregional DFS was more superior in the chemoradiation arm compared to radiotherapy alone (67 vs $54 \%$, respectively). The 5-year OS rate was reported to be $48 \%$ in the chemoradiation arm compared to $35 \%$ in the radiotherapy group (HR, 0.82; $95 \%$ CI $0.63-1.09 ; p=$ $0.16)$. Acute toxic effects were also shown not to reach statistical significance in relation to grades 3 and 4 outcomes $(27.5 \%$ vs $365, p=0.07)$. Bladder volume irradiated did however correspond to risk of grade 3 or 4 toxicity. Bladder function, an important contributor to quality of life, was demonstrated not to be significantly more impaired in the chemoradiotherapy arm. Good long-term bladder function and low rates of salvage cystectomy suggest that the use of chemoradiotherapy in BC patients who are often frail, with multiple comorbidities, appears to be of significant benefit.

Hoskin et al. compared 333 patients with locally advanced BC in a phase III trial receiving either radiotherapy alone (schedule of either 55 Gy in 20 fractions in 4 weeks or 64 Gy in 32 fractions in 6.5 weeks) or synchronous chemoradiation (carbogen and nicotinamide). Chemoradiotherapy showed a non-significant improvement in the primary end point (cystoscopic control at 6 months) compared to radiotherapy alone ( 81 vs $76 \%, p=0.3$ ) [75••]. Differences in 3-year OS ( 59 vs $46 \%, p=0.05)$, risk of death ( $14 \%$ lower, $p=$ $0.04)$ and local relapse $(p=0.05)$ were significantly in favour of chemoradiotherapy. There was no difference in acute bowel and urinary events between the two groups. Late events only show an increase in morbidity of grade 2 or worse stool frequency in the treatment group. This randomised control trial showed that the use of radiotherapy with concurrent chemotherapy using nicotinamide and carbogen demonstrates a schedule which has acceptable levels of toxicity, comparable with what is encountered with radiotherapy alone.
Some therapeutic gain can be concluded from this study, although non-significant improvements in locoregional control may suggest the need for further radiosensitizers, e.g., cisplatin, different to that of the hypoxic modification mechanism of nicotinamide and carbogen.

Taken together, trial data with chemoradiation suggests tolerability in those with poorer renal function and other existing co-morbidities whether treated with the North American trimodality approach [72] or the UK single treatment block [36••]. Other phase III studies have also demonstrated encouraging results (Table 2).

\section{Quality of Life and Toxicity of Organ Preservation}

It is important to mention that perioperative morbidity and mortality of salvage cystectomy after previous bladder chemoradiation is very similar to that of primary

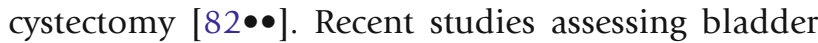
function in trimodality approaches have demonstrated in 71 patients (median follow-up 6.3 years) that $75 \%$ had normally functioning bladders based on urodynamic studies and $85 \%$ reported no urgency [83]. It is important to comment that quality of life and treatment toxicity depend on treatment regimens. Patient preference and likelihood of treatment success should drive modality selection. It is however important to consider the benefit of organ preservation over radial cystectomy. Several quality of life studies have evaluated the reconstructive methods of RC. A Japanese study assessed 85 patients post-reconstructive cystectomy (orthotopic bladder or ileal conduit) [84]. No significant difference was found between the modality of reconstruction; however, when compared with the general population in the USA, general health and social functioning was significantly lower. Another major concern following RC is erectile dysfunction; studies have shown an overall increase in erectile dysfunction, even in nervesparing surgery $[85,86]$.

\section{Future Directions}

In an effort to improve OS and better control of locoregional disease, novel approaches have been trialed. The use of hyperfractionated radiotherapy is one such approach. The RTOG protocol 07-12 studied the use of hyperfractionated radiotherapy (twice daily) with concurrent cisplatin therapy which achieved a complete response of $>85 \%$ [87]. Other studies, however, comparing chemoradiation with radiation alone using two fractionation schemes have demonstrated no difference

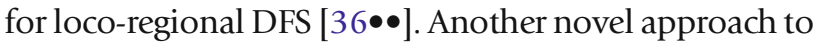




\begin{tabular}{|c|c|c|c|c|c|c|}
\hline Study & $\mathrm{n}$ & $\begin{array}{l}\text { Tumour } \\
\text { grade }\end{array}$ & Methods & $\begin{array}{l}\text { Complete } \\
\text { response } \\
\text { rate }\end{array}$ & Results & Ref \\
\hline $\begin{array}{l}\text { Hoskin } \\
\text { et al. }\end{array}$ & 333 & T2-T4a & $\begin{array}{l}\text { Radiotherapy ( } 55 \mathrm{~Gy} \text { in } 20 \text { fractions in } \\
4 \text { weeks or } 64 \mathrm{~Gy} \text { in } 32 \text { fractions in } \\
6.5 \text { weeks) + nicotinamide ( } 60 \text { or } \\
40 \mathrm{mg} / \mathrm{kg} \text { given } 1.5-2 \mathrm{~h} \text { before each } \\
\text { fraction) + carbogen ( } 2 \% \mathrm{CO}_{2} \text { and } \\
98 \% \mathrm{O}_{2} \text { at } 15 \mathrm{~L} / \text { min administered } \\
5 \text { min before and during } \\
\text { radiotherapy) vs radiotherapy alone }\end{array}$ & $\begin{array}{l}81 \text { vs } 76 \% \\
\qquad(p= \\
0.3)\end{array}$ & $\begin{array}{l}3 \text {-year overall survival } \\
59 \text { vs } 46 \%(p=0.04)\end{array}$ & {$[75 \bullet \bullet]$} \\
\hline $\begin{array}{l}\text { Coppin } \\
\text { et al. }\end{array}$ & 99 & $\begin{array}{l}\text { T2-T4b } \\
\text { N0 }\end{array}$ & $\begin{array}{l}\text { Radiotherapy (fractionated continuous } \\
\text { pelvic radiation) + cisplatin } \\
100 \mathrm{mg} / \mathrm{m}^{2} \text { at 2-week intervals for } \\
\text { three cycles concurrent with } \\
\text { radiation vs radiotherapy alone }\end{array}$ & 47 vs $31 \%$ & $\begin{array}{l}\text { 3-year overall survival } 47 \text { vs } 33 \% \\
\text { 5-year locoregional relapse } \\
\text { rate } 40 \text { vs } 59 \%(p=0.04) \\
\text { bladder preservation } 70 \text { vs } \\
36 \%\end{array}$ & [57] \\
\hline $\begin{array}{l}\text { James } \\
\text { et al. }\end{array}$ & 360 & $\begin{array}{l}\text { T2-T4a } \\
\text { N0 }\end{array}$ & $\begin{array}{l}\text { Concominant chemoradiotherapy (5FU } \\
500 \mathrm{mg} / \mathrm{m}^{2} / \text { day during fractions } \\
1-5 \text { and } 16-20 \text { and mitomycin C } \\
12 \mathrm{mg} / \mathrm{m}^{2}+\text { whole bladder } \\
\text { radiotherapy/modified volume } \\
\text { radiotherapy) vs radiotherapy alone }\end{array}$ & & $\begin{array}{l}\text { 5-year overall survival } 48 \text { vs } 35 \% \\
\qquad(p=0.16) \\
\text { 2-year disease-specific survival } 67 \\
\text { vs } 54 \%(p=0.03)\end{array}$ & {$[36 \bullet \bullet]$} \\
\hline $\begin{array}{l}\text { Tunio } \\
\text { et al. }\end{array}$ & 230 & $\begin{array}{l}\text { T2-T4 } \\
\text { N0/Nx }\end{array}$ & $\begin{array}{l}\text { Concomitant chemoradiotherapy with } \\
\text { whole pelvis radiotherapy vs } \\
\text { bladder-only radiotherapy }\end{array}$ & $\begin{array}{l}93 \text { vs } 96 \% \\
\quad(p= \\
0.05)\end{array}$ & $\begin{array}{l}\text { 5-year overall survival } 52.9 \text { vs } \\
\quad 51 \%(p=0.8) \\
5 \text {-year disease-specific survival } \\
47.1 \text { vs } 46.9 \%(p=0.5) \\
\text { Bladder preservation rates } 58.9 \text { vs } \\
57.1 \%(p=0.8)\end{array}$ & {$[81 \bullet]$} \\
\hline
\end{tabular}

radiotherapy that has been used is image-guided radiation therapy (IGRT): this conformal radiotherapy more accurately targets tumours in mobile organs like the bladder [88]. Here, three to four gold markers are implanted into the bladder during TURBT and then tracked during radiotherapy. This allows the radiographer to ensure the tumour is within the desired radiotherapy field. However, these plates can often cause pain or fall out altogether [89]. An alternative to this approach is using the contrast agent lipodol. This works in the same way as plate insertion in that during TURBT, lipodol is injected into the tumour sites and radiotherapy can then focus its field of treatment. This use of IGRT is ideal as it can dictate everyday radiotherapy based on the location of the tumour within the bladder [89]. Bladders will change in shape and size depending on bowel distention and the volume of urine in the bladder. Some agents are currently being investigated for use alongside radiotherapy. Chakravarti et al. demonstrated that there is significant correlation between reduced response rate and HER2/neu overexpression [90]. HER2/neu positivity can be found in $40-80 \%$ of bladder tumours. Hussain et al. reported in a multicenter phase II trial using trastuzumab, carboplatin, gemcitabine and paclitaxel in advanced metastatic urothelial carcinoma patients, with a median time to progression and survival of 9.3 and 14.1 months, respectively [91]. This study demonstrated feasibility; however, toxicity rates, especially cardiac toxicity, were high. Theoretically, there may therefore be a role of trastuzumab therapy in HER2/neu-positive bladder tumours in combination with radiation therapy to further improve on organ preservation strategies.

Overexpression of EGFR has been found to be significantly correlated to high tumour stage and poor patient outcome [92]. EGFR expression, however, as a predictor 
of prognosis, was not independent of stage. The TUXEDO trial, a phase I/II trial, is currently underway in UK, examining combination therapy of cetuximab with 5FU and mitomycin $\mathrm{C}$ with concurrent radiotherapy in MIBC.

Azuma et al. demonstrated in a recent trial of 134 patients receiving cystectomy or a bladder-preserving OMC/BOAI-gemcitabine regimen for locally invasive BC, a15-year OS of $40 \%$ compared to $79.7 \%$ in the bladder-preserving study arm [93•]. This novel form of bladder preservation therapy involves using balloonoccluded arterial infusion (BOAI) of a chemotherapeutic agent (cisplatin/gemcitabine), used concomitantly with haemodialysis and radiotherapy (known as the Osaka Medical College [OMC] regimen). This method maximises the concentration of the chemotherapeutic agent at the site of the tumour without the systemic adverse effects experienced by routine chemotherapy [94]. This method, however, can lead to the development of pelvic neuropathy. This bladder-preserving regimen can be curative in patients where both cystectomy is indicated and in those where curative treatment was previously not a possibility.

Currently the use of the tumour staging system (TNM) is insufficient to predict outcome in patients with $\mathrm{BC}$ irrespective of the treatment they receive. Molecular prognostic markers should be evaluated in randomised control trials in order to define their role in clinical outcome measures.

\section{Conclusion}

Concurrent chemoradiotherapy may appear to give results equivalent to those of radical surgery with regards to local control; however, it seems to be more superior when considering quality of life. It represents an alternative for patients who decline cystectomy or where cystectomy is contraindicated. No randomised trial as of yet has directly compared bladder-preserving chemoradiotherapy with cystectomy, and therefore a definitive answer to the age-old question of superiority of one modality over other remains unanswered. One needs to understand that both organ preservation treatment and radical cystectomy are complimentary treatments rather than competing treatments. Patients opting for organ preservation need to be counselled about long-term requirement of cystoscopic surveillance and risk of losing their bladder and salvage cystectomy even decades after organ preservation therapy. The success of recent trials within the field of bladder preservation has been possible due to the meticulous selection criteria applied compared with those from previous decades. Although many chemoradiation protocols exist in the literature, few direct comparisons exist.

\section{Compliance with Ethical Standards}

\section{Conflict of Interest}

Omar M.S. El-Taji declares that he has no conflict of interest.

Sameer Alam declares that he has no conflict of interest.

Syed A Hussain has received financial support through grants from Bayer, Pierre Fabre and Boehringer Ingelheim; has received compensation from Astellas (advisory board), Bayer (consultancy) and Pierre Fabre (consultancy); and has receive non-financial support from Bayer, Janssen and Boehringer Ingelheim. 


\section{Human and Animal Rights and Informed Consent}

This article does not contain any studies with human or animal subjects performed by any of the authors.

Open Access This article is distributed under the terms of the Creative Commons Attribution 4.0 International License (http://creativecommons.org/licenses/by/4.0/), which permits unrestricted use, distribution, and reproduction in any medium, provided you give appropriate credit to the original author(s) and the source, provide a link to the Creative Commons license, and indicate if changes were made.

\section{References}

Papers of particular interest, published recently, have been highlighted as:

- Of importance

$\bullet \quad$ Of major importance

1. Ferlay J, Soerjomataram I, Ervik M, Dikshit R, Eser S, Mathers C, Rebelo M, Parkin DM, Forman D, Bray, F. GLOBOCAN 2012 v1.0, Cancer Incidence and Mortality Worldwide: IARC CancerBase No. 11 [Internet]. Lyon, France: International Agency for Research on Cancer; 2013. Available from: http://globocan.iarc.fr [Accessed August 2015].

2. American Cancer Society. What are the key statistics about bladder cancer? Available from: http://www. cancer.org/cancer/bladdercancer/detailedguide/ bladder-cancer-key-statistics [Accessed August 2015].

3. Burger M, Catto JW, Dalbagni G, Grossman HB, Herr H, Karakiewicz P, et al. Epidemiology and risk factors of urothelial bladder cancer. Eur Urol. 2013;63(2):234-41.

4. Cancer Research UK. Bladder Cancer Survival Statistics; Available from: www.cancerresearchuk.org/cancerinfo/cancerstats/?=5441 [Accessed August 2015].

5. Stenzl A, Cowan NC, De Santis M, Kuczyk MA, Merseburger AS, Ribal MJ, et al. Treatment of muscleinvasive and metastatic bladder cancer: update of the EAU guidelines. Eur Urol. 2011;59(6):1009-18.

6. Sievert KD, Amend B, Nagele U, Schilling D, Bedke J, Horstmann $\mathrm{M}$, et al. Economic aspects of bladder cancer: what are the benefits and costs? World J Urol. 2009;27:295-300.

7. Whitmore Jr WF. Management of invasive bladder neoplasms. Semin Urol. 1983;1(1):34-41.

8. Cody JD, Nabi G, Dublin N, McClinton S, Neal DE, Pickard $\mathrm{R}$, et al. Urinary diversion and bladder reconstruction/replacement using intestinal segments for intractable incontinence or following cystectomy. Cochrane Database Syst Rev. 2012;2, CD003306.

9. Parekh DJ, Donat SM. Urinary diversion: options, patient selection, and outcomes. Semin Oncol. 2007;34(2):98-109.

10. Basic DT, Hadzi-Djokic J, Ignjatovic I. The history of urinary diversion. Acta Chir Iugosl. 2007;54(4):9-17.

11. Shimko MS, Tollefson MK, Umbreit EC, Farmer SA, Blute ML, Frank I. Long-term complications of conduit urinary diversion. J Urol. 2011;185(2):562-7.
12. Hyndman ME, Kaye D, Field NC, Lawson KA, Smith $\mathrm{ND}$, Steinberg GD, et al. The use of regenerative medicine in the management of invasive bladder cancer. Adv Urol. 2012;2012:653652.

13. el Khalil SA. Long term complications following ileal conduit urinary diversion after radical cystectomy. J Egypt Natl Canc Inst. 2010;22(1):13-8.

14. Aghazadeh MA, Barocas DA, Salem S, Clark PE, Cookson MS, Davis R, et al. Determining factors for hospital discharge status after radical cystectomy in a large contemporary cohort. J Urol. 2011;185(1):85-9.

15. Rosario DJ, Becker M, Anderson JB. The changing pattern of mortality and morbidity from radical cystectomy. BJU Int. 2000;85(4):427-30.

16. Goodney PP, Stukel TA, Lucas FL, Finlayson EV, Birkmeyer JD. Hospital volume, length of stay, and readmission rates in high-risk surgery. Ann Surg. 2003;238(2):161-7.

17. Madersbacher S, Schmidt J, Eberle JM, Thoeny HC, Burkhard F, Hochreiter W, et al. Long-term outcome of ileal conduit diversion. J Urol. 2003;169(3):985-90.

18. El-Taji OM, Khattak AQ, Hussain SA. Bladder reconstruction: the past, present and future. Oncol Lett. 2015;10(1):3-10.

19. Shipley WU, Rose MA, Perrone TL, Mannix CM, Heney NM, Prout Jr GR. Full-dose irradiation for patients with invasive bladder carcinoma: clinical and histological factors prognostic of improved survival. J Urol. 1985;134(4):679-83.

20. Pollack A, Zagars GZ. Radiotherapy for stage T3b transitional cell carcinoma of the bladder. Semin Urol Oncol. 1996;14(2):86-95.

21. De Neve W, Lybeert ML, Goor C, Crommelin MA, Ribot JG. Radiotherapy for T2 and T3 carcinoma of the bladder: the influence of overall treatment time. Radiother Oncol. 1995;36(3):183-8.

22. Mameghan H, Fisher R, Mameghan J, Brook S. Analysis of failure following definitive radiotherapy for invasive transitional cell carcinoma of the bladder. Int J Radiat Oncol Biol Phys. 1995;31(2):247-54.

23. Jenkins BJ, Caulfield MJ, Fowler CG, Badenoch DF, Tiptaft RC, Paris AM, et al. Reappraisal of the role of 
radical radiotherapy and salvage cystectomy in the treatment of invasive (T2/T3) bladder cancer. Br J Urol. 1988;62(4):343-6.

24. Douglas RM, Kaufman DS, Zietman AL, Althausen AF, Heney NM, Shipley WU. Conservative surgery, patient selection, and chemoradiation as organ-preserving treatment for muscle-invading bladder cancer. Semin Oncol. 1996;23(5):614-20.

25. Grob BM, Macchia RJ. Radical transurethral resection in the management of muscle-invasive bladder cancer. J Endourol. 2001;15(4):419-23. discussion 25-6.

26. Mydlo JH, Weinstein R, Shah S, Solliday M, Macchia RJ. Long-term consequences from bladder perforation and/or violation in the presence of transitional cell carcinoma: results of a small series and a review of the literature. J Urol. 1999;161(4):1128-32.

27. Pagano F, Bassi P, Galetti TP, Meneghini A, Milani C, Artibani W, et al. Results of contemporary radical cystectomy for invasive bladder cancer: a clinicopathological study with an emphasis on the inadequacy of the tumor, nodes and metastases classification. J Urol. 1991;145(1):45-50.

28. Stein JP, Lieskovsky G, Cote R, Groshen S, Feng AC, Boyd $\mathrm{S}$, et al. Radical cystectomy in the treatment of invasive bladder cancer: long-term results in 1,054 patients. J Clin Oncol. 2001;19(3):666-75.

29. Thrasher JB, Frazier HA, Robertson JE, Paulson DF. Does of stage pT0 cystectomy specimen confer a survival advantage in patients with minimally invasive bladder cancer? J Urol. 1994;152(2 Pt 1):393-6.

30. Volkmer BG, Kuefer R, Bartsch Jr G, Straub M, de Petriconi R, Gschwend JE, et al. Effect of a pT0 cystectomy specimen without neoadjuvant therapy on survival. Cancer. 2005;104(11):2384-91.

31. Karakiewicz PI, Shariat SF, Palapattu GS, Perrotte P, Lotan Y, Rogers CG, et al. Precystectomy nomogram for prediction of advanced bladder cancer stage. Eur Urol. 2006;50(6):1254-60. discussion 61-2.

32. Kibel AS, Dehdashti F, Katz MD, Klim AP, Grubb RL, Humphrey PA, et al. Prospective study of [18F]fluorodeoxyglucose positron emission tomography/computed tomography for staging of muscle-invasive bladder carcinoma. J Clin Oncol. 2009;27(26):4314-20.

33. Herr HW. Transurethral resection of muscle-invasive bladder cancer: 10-year outcome. J Clin Oncol. 2001;19(1):89-93.

34. Solsona E, Iborra I, Collado A, Rubio-Briones J, Casanova J, Calatrava A. Feasibility of radical transurethral resection as monotherapy for selected patients with muscle invasive bladder cancer. J Urol. 2010;184(2):475-80.

35. Leibovici D, Kassouf W, Pisters LL, Pettaway CA, Wu X, Dinney CP, et al. Organ preservation for muscleinvasive bladder cancer by transurethral resection. Urology. 2007;70(3):473-6.

$36 . \bullet$ James ND, Hussain SA, Hall E, Jenkins P, Tremlett J, Rawlings C, et al. Radiotherapy with or without chemotherapy in muscle-invasive bladder cancer. $\mathrm{N}$ Engl J Med. 2012;366(16):1477-88.

This was the largest organ preservation study in bladder cancer and demonstrated in a phase III RCT comparing synchronous chemoradiation with radiotherapy that chemoradiation significantly improved locoregional control of BC with no significant increase in adverse events compared with radiotherapy alone.

37. Moonen L, vd Voet $\mathrm{H}$, de Nijs R, Horenblas S, Hart AA, Bartelink H. Muscle-invasive bladder cancer treated with external beam radiation: influence of total dose, overall treatment time, and treatment interruption on local control. Int J Radiat Oncol Biol Phys. 1998;42(3):525-30.

38. Greven KM, Solin LJ, Hanks GE. Prognostic factors in patients with bladder carcinoma treated with definitive irradiation. Cancer. 1990;65(4):908-12.

39. Majewski W, Tarnawski R. Acute and late toxicity in radical radiotherapy for bladder cancer. Clin Oncol ( $R$ Coll Radiol). 2009;21(8):598-609.

40. Fossa SD, Aass N, Ous S, Waehre H, Ilner K, Hannisdal E. Survival after curative treatment of muscle-invasive bladder cancer. Acta Oncol. 1996;35 Suppl 8:59-65.

41. Rosenberg JE, Carroll PR, Small EJ. Update on chemotherapy for advanced bladder cancer. J Urol. 2005;174(1):14-20.

42. Cooke PW, Dunn JA, Latief T, Bathers S, James ND, Wallace DM. Long-term risk of salvage cystectomy after radiotherapy for muscle-invasive bladder cancer. Eur Urol. 2000;38(3):279-86.

43. Duncan W, Quilty PM. The results of a series of 963 patients with transitional cell carcinoma of the urinary bladder primarily treated by radical megavoltage X-ray therapy. Radiother Oncol. 1986;7(4):299-310.

44. Gospodarowicz MK, Quilty PM, Scalliet P, Tsujii H, Fossa SD, Horenblas S, et al. The place of radiation therapy as definitive treatment of bladder cancer. Int J Urol. 1995;2 Suppl 2:41-8.

45. Pollack A, Zagars GK, Swanson DA. Muscle-invasive bladder cancer treated with external beam radiotherapy: prognostic factors. Int J Radiat Oncol Biol Phys. 1994;30(2):267-77.

46. Choueiri TK, Raghavan D. Chemotherapy for muscleinvasive bladder cancer treated with definitive radiotherapy: persisting uncertainties. Nat Clin Pract Oncol. 2008;5(8):444-54.

47. Housset M, Maulard C, Chretien Y, Dufour B, Delanian $\mathrm{S}$, Huart J, et al. Combined radiation and chemotherapy for invasive transitional-cell carcinoma of the bladder: a prospective study. J Clin Oncol. 1993;11(11):2150-7.

48. Rodel C, Grabenbauer GG, Kuhn R, Papadopoulos T, Dunst J, Meyer M, et al. Combined-modality treatment and selective organ preservation in invasive bladder cancer: long-term results. J Clin Oncol. 2002;20(14):3061-71.

49. Majewski W, Maciejewski B, Majewski S, Suwinski R, Miszczyk L, Tarnawski R. Clinical radiobiology of stage 
T2-T3 bladder cancer. Int J Radiat Oncol Biol Phys. 2004;60(1):60-70.

50. Hayter CR, Paszat LF, Groome PA, Schulze K, Mackillop WJ. The management and outcome of bladder carcinoma in Ontario, 1982-1994. Cancer. 2000;89(1):142-51.

51. Munro NP, Sundaram SK, Weston PM, Fairley L, Harrison SC, Forman D, et al. A 10-year retrospective review of a nonrandomized cohort of 458 patients undergoing radical radiotherapy or cystectomy in Yorkshire, UK. Int J Radiat Oncol Biol Phys. 2010;77(1):119-24.

52. Hall RR. International Collaboration of Trialist of the MRC. Updated results of a randomised controlled trial of neoadjuvant cisplatin, methotrexate and vinblastine chemotherapy for muscle invasive bladder cancer. Proc Am Soc Clin Oncol. 2002;21:178.

53. International Collaboration of $\mathrm{T}$, Medical Research Council Advanced Bladder Cancer Working P, European Organisation for R, Treatment of Cancer GenitoUrinary Tract Cancer G, Australian Bladder Cancer Study G, National Cancer Institute of Canada Clinical Trials $\mathrm{G}$ et al. International phase III trial assessing neoadjuvant cisplatin, methotrexate, and vinblastine chemotherapy for muscle-invasive bladder cancer: long-term results of the BA06 30894 trial. J Clin Oncol. 2011;29(16):2171-7.

54. Grossman HB, Natale RB, Tangen CM, Speights VO, Vogelzang NJ, Trump DL, et al. Neoadjuvant chemotherapy plus cystectomy compared with cystectomy alone for locally advanced bladder cancer. N Engl J Med. 2003;349(9):859-66.

55. Bellmunt J, von der Maase H, Mead GM, Skoneczna I, De Santis M, Daugaard G, et al. Randomized phase III study comparing paclitaxel/cisplatin/gemcitabine and gemcitabine/cisplatin in patients with locally advanced or metastatic urothelial cancer without prior systemic therapy: EORTC Intergroup Study 30987. J Clin Oncol. 2012;30(10):1107-13.

56. Chung PW, Bristow RG, Milosevic MF, Yi QL, Jewett $\mathrm{MA}$, Warde PR, et al. Long-term outcome of radiationbased conservation therapy for invasive bladder cancer. Urol Oncol. 2007;25(4):303-9.

57. Coppin CM, Gospodarowicz MK, James K, Tannock IF, Zee B, Carson J, et al. Improved local control of invasive bladder cancer by concurrent cisplatin and preoperative or definitive radiation. The National Cancer Institute of Canada Clinical Trials Group. J Clin Oncol. 1996;14(11):2901-7.

58. Sangar VK, McBain CA, Lyons J, Ramani VA, Logue JP, Wylie JP, et al. Phase I study of conformal radiotherapy with concurrent gemcitabine in locally advanced bladder cancer. Int J Radiat Oncol Biol Phys. 2005;61(2):420-5.

59. Shipley WU, Kaufman DS, Zehr E, Heney NM, Lane SC, Thakral HK, et al. Selective bladder preservation by combined modality protocol treatment: long-term outcomes of 190 patients with invasive bladder cancer. Urology. 2002;60(1):62-7. discussion 7-8.
60. Wallmeroth A, Wagner U, Moch H, Gasser TC, Sauter G, Mihatsch MJ. Patterns of metastasis in muscleinvasive bladder cancer (pT2-4): an autopsy study on 367 patients. Urol Int. 1999;62(2):69-75.

61. Basavaraju SR, Easterly CE. Pathophysiological effects of radiation on atherosclerosis development and progression, and the incidence of cardiovascular complications. Med Phys. 2002;29(10):2391-403.

62. Bentzen SM, Harari PM, Bernier J. Exploitable mechanisms for combining drugs with radiation: concepts, achievements and future directions. Nat Clin Pract Oncol. 2007;4(3):172-80.

63. Hagan MP, Winter KA, Kaufman DS, Wajsman Z, Zietman AL, Heney NM, et al. RTOG 97-06: initial report of a phase I-II trial of selective bladder conservation using TURBT, twice-daily accelerated irradiation sensitized with cisplatin, and adjuvant MCV combination chemotherapy. Int J Radiat Oncol Biol Phys. 2003;57(3):665-72.

64. Shipley WU, Prout Jr GR, Einstein AB, Coombs LJ, Wajsman Z, Soloway MS, et al. Treatment of invasive bladder cancer by cisplatin and radiation in patients unsuited for surgery. JAMA. 1987;258(7):931-5.

65. Marks LB, Kaufman SD, Prout Jr GR, Heney NM, Griffin PP, Shipley WU. Invasive bladder carcinoma: preliminary report of selective bladder conservation by transurethral surgery, upfront MCV (methotrexate, cisplatin, and vinblastine) chemotherapy and pelvic irradiation plus cisplatin. Int J Radiat Oncol Biol Phys. 1988;15(4):877-83.

66. Shipley WU. Cisplatin and external beam radiation in patients with invasive bladder cancer. Int J Radiat Oncol Biol Phys. 1989;16(6):1649-50.

67. Prout Jr GR, Shipley WU, Kaufman DS, Heney NM, Griffin PP, Althausen AF, et al. Preliminary results in invasive bladder cancer with transurethral resection, neoadjuvant chemotherapy and combined pelvic irradiation plus cisplatin chemotherapy. J Urol. 1990;144(5):1128-34. discussion 34-6.

68. Prout Jr GR, Shipley WU, Kaufman DS, Griffin PP, Heney NM. Interval report of a phase I-II study utilizing multiple modalities in the treatment of invasive bladder cancer. A bladder-sparing trial. Urol Clin North Am. 1991;18(3):547-54.

69. Kaufman DS, Shipley WU, Althausen AF. Radiotherapy and chemotherapy in invasive bladder cancer with potential bladder sparing. Hematol Oncol Clin North Am. 1992;6(1):179-94.

70. Shipley WU, Kaufman DS, Heney NM, Althausen AF, Zietman AL. An update of combined modality therapy for patients with muscle invading bladder cancer using selective bladder preservation or cystectomy. J Urol. 1999;162(2):445-50. discussion 50-1.

71. Zietman AL, Shipley WU, Kaufman DS. Organconserving approaches to muscle-invasive bladder cancer: future alternatives to radical cystectomy. Ann Med. 2000;32(1):34-42.

72. Efstathiou JA, Bae K, Shipley WU, Kaufman DS, Hagan $\mathrm{MP}$, Heney NM, et al. Late pelvic toxicity after bladder- 
sparing therapy in patients with invasive bladder cancer: RTOG 89-03, 95-06, 97-06, 99-06. J Clin Oncol. 2009;27(25):4055-61

73. Hussain SA, Moffitt DD, Glaholm JG, Peake D, Wallace DM, James ND. A phase I-II study of synchronous chemoradiotherapy for poor prognosis locally advanced bladder cancer. Ann Oncol. 2001;12(7):929-35.

74. Choudhury A, Swindell R, Logue JP, Elliott PA, Livsey JE, Wise M, et al. Phase II study of conformal hypofractionated radiotherapy with concurrent gemcitabine in muscle-invasive bladder cancer. J Clin Oncol. 2011;29(6):733-8.

75.• Hoskin PJ, Rojas AM, Bentzen SM, Saunders MI. Radiotherapy with concurrent carbogen and nicotinamide in bladder carcinoma. J Clin Oncol. 2010;28(33):4912-8. RT + CON produced a small nonsignificant improvement in $\mathrm{CC}_{6 \mathrm{~m}}$. Differences in OS, risk of death, and local relapse were significantly in favor of RT + CON. Late morbidity was similar in both trial arms. Results indicate a benefit of adding CON to radical RT.

76. Al-Sarraf M, Martz K, Herskovic A, Leichman L, Brindle JS, Vaitkevicius VK, et al. Progress report of combined chemoradiotherapy versus radiotherapy alone in patients with esophageal cancer: an intergroup study. J Clin Oncol. 1997;15(1):277-84.

77. Haffty BG, Son YH, Papac R, Sasaki CT, Weissberg JB, Fischer D, et al. Chemotherapy as an adjunct to radiation in the treatment of squamous cell carcinoma of the head and neck: results of the Yale Mitomycin Randomized Trials. J Clin Oncol. 1997;15(1):268-76.

78. Epidermoid anal cancer: results from the UKCCCR randomised trial of radiotherapy alone versus radiotherapy, 5-fluorouracil, and mitomycin. UKCCCR Anal Cancer Trial Working Party. UK Co-ordinating Committee on Cancer Research. Lancet. 1996; 348(9034):1049-54.

79. Galsky MD, Hahn NM, Rosenberg J, Sonpavde G, Hutson T, Oh WK, et al. Treatment of patients with metastatic urothelial cancer "unfit" for Cisplatinbased chemotherapy. J Clin Oncol.

2011;29(17):2432-8.

80. Hussain SA, Stocken DD, Peake DR, Glaholm JG Zarkar A, Wallace DM, et al. Long-term results of a phase II study of synchronous chemoradiotherapy in advanced muscle invasive bladder cancer. Br J Cancer. 2004;90(11):2106-11.

81. Tunio MA, Hashmi A, Qayyum A, Mohsin R, Zaeem A. Whole-pelvis or bladder-only chemoradiation for lymph node-negative invasive bladder cancer: singleinstitution experience. Int J Radiat Oncol Biol Phys. 2012;82(3):e457-62.

This study showed that BO-CCRT had similar rates of bladder preservation, disease-free survival, and overall survival rates as those of WP-CCRT. Smaller field sizes including bladder can be used as bladder preservation protocol for patients with muscleinvasive lymph node-negative bladder cancer to minimize the side effects of CCRT.
82.•• Eswara JR, Efstathiou JA, Heney NM, Paly J, Kaufman DS, McDougal WS, et al. Complications and long-term results of salvage cystectomy after failed bladder sparing therapy for muscle invasive bladder cancer. J Urol. 2012;187(2):463-8.

This study demonstrated that perioperative morbidity and mortality of salvage cystectomy after previous bladder chemoradiation is similar to that of primary cystectomy. Immediate cystectomies have more cardiovascular/hematological complications while delayed cystectomies have more tissue healing complications.

83. Zietman AL, Sacco D, Skowronski U, Gomery P, Kaufman DS, Clark JA, et al. Organ conservation in invasive bladder cancer by transurethral resection, chemotherapy and radiation: results of a urodynamic and quality of life study on long-term survivors. J Urol. 2003;170(5):1772-6.

84. Hara I, Miyake H, Hara S, Gotoh A, Nakamura I, Okada $\mathrm{H}$, et al. Health-related quality of life after radical cystectomy for bladder cancer: a comparison of ileal conduit and orthotopic bladder replacement. BJU Int. 2002;89(1):10-3.

85. Zippe CD, Raina R, Massanyi EZ, Agarwal A, Jones JS, Ulchaker J, et al. Sexual function after male radical cystectomy in a sexually active population. Urology. 2004;64(4):682-5. discussion 5-6.

86. Henningsohn L, Steven K, Kallestrup EB, Steineck G. Distressful symptoms and well-being after radical cystectomy and orthotopic bladder substitution compared with a matched control population. J Urol. 2002;168(1):168-74. discussion 74-5.

87. Widmark A, Flodgren P, Damber JE, Hellsten S, Cavallin-Stahl E. A systematic overview of radiation therapy effects in urinary bladder cancer. Acta Oncol. 2003;42(5-6):567-81.

88. Redpath AT, Muren LP. CT-guided intensity-modulated radiotherapy for bladder cancer: isocentre shifts, margins and their impact on target dose. Radiother Oncol. 2006;81(3):276-83.

89. Sondergaard J, Olsen KO, Muren LP, Elstrom UV, Grau C, Hoyer M. A study of image-guided radiotherapy of bladder cancer based on lipiodol injection in the bladder wall. Acta Oncol. 2010;49(7):1109-15.

90. Chakravarti A, Winter K, Wu CL, Kaufman D, Hammond E, Parliament M, et al. Expression of the epidermal growth factor receptor and Her-2 are predictors of favorable outcome and reduced complete response rates, respectively, in patients with muscle-invading bladder cancers treated by concurrent radiation and cisplatin-based chemotherapy: a report from the Radiation Therapy Oncology Group. Int J Radiat Oncol Biol Phys. 2005;62(2):309-17.

91. Hussain MH, MacVicar GR, Petrylak DP, Dunn RL, Vaishampayan U, Lara Jr PN, et al. Trastuzumab, paclitaxel, carboplatin, and gemcitabine in advanced human epidermal growth factor receptor-2/neu-positive urothelial carcinoma: results of a multicenter phase II 
National Cancer Institute trial. J Clin Oncol. 2007;25(16):2218-24.

92. Nguyen PL, Swanson PE, Jaszcz W, Aeppli DM, Zhang $\mathrm{G}$, Singleton TP, et al. Expression of epidermal growth factor receptor in invasive transitional cell carcinoma of the urinary bladder. A multivariate survival analysis. Am J Clin Pathol. 1994;101(2):166-76.

93. Azuma H, Inamoto T, Takahara K, Nomi H, Hirano $\mathrm{H}_{\text {, }}$ Uehara $\mathrm{H}$, et al. A great option for elderly patients with locally invasive bladder cancer, BOAI-CDDP-radiation (OMC regimen). Int J Oncol. 2013;43(4):1087-94.
This study demonstrated in a recent trial of 134 patients receiving cystectomy or a novel form of bladder preservation (using OMC/BOAI-gemcitabin) for locally-invasive BC, a15year OS difference of almost $40 \%$ in favour of the bladder preserving study arm.

94. Azuma H, Inamoto $\mathrm{T}$, Ibuki $\mathrm{N}$, Ubai $\mathrm{T}$, Kotake $\mathrm{Y}$, Takahara $\mathrm{K}$, et al. Utility of the novel bladder preservation therapy, BOAI-CDDP-radiation (OMC-regimen), for elderly patients with invasive bladder cancer. Int J Oncol. 2011;38(1): $13-24$. 